\title{
Effect of corrosion damage on the performance level of a 25-year-old reinforced concrete building
}

\author{
Hakan Yalciner*, Serhan Sensoy and Ozgur Eren \\ Civil Engineering Department, Eastern Mediterranean University, Gazimagusa, Mersin, Turkey
}

\begin{abstract}
Corrosion is a long-term process resulting in the deterioration of the reinforced concrete (RC) structures. Most of the structural problems observed under the impact of either earthquakes or service loads might occur due to corrosion. Therefore, prediction of the remaining service life of a corroding RC structure plays an important role to prevent serious premature damage. In this study, a corroded, 25-year-old high school building which has been demolished at an earlier time was analyzed as a function of corrosion rate. Bond-slip relationships were taken into account in nonlinear analyses as a function of corrosion rate for different time periods (i.e., non-corroded ( $\mathrm{t}: 0$ ), existing ( $\mathrm{t}: 25)$ and 50 years after construction); and they were used to ensure the effect of time-dependent slip rotation on the global structural behaviour by modifying the target post-yield stiffness of each structural member. Nonlinear push-over analyses were performed by defining the time-dependent plastic hinge properties as a consequence of corrosion effects. In order to define the performance levels of three different time periods, nonlinear incremental dynamic analyses (IDA) were performed for 20 earthquake ground motion records as a function of corrosion rate. Results showed that bond-slip relationship between concrete and steel is very important in evaluating the non-linear behaviour of corroded RC structures.
\end{abstract}

Keywords: Incremental dynamic analysis, corrosion, bond-slip, performance level

\section{Introduction}

Corrosion of reinforcing steel in concrete is the predominant causal factor in the premature degradation of $\mathrm{RC}$ structures [1]. Once reinforcement corrosion is initiated, expected seismic performance levels of a RC structure reduce due to different effects of corrosion. At this point, it is important to decide that what kind of corrosion effects are needed to be taken into account during the assessment of non-linear seismic performance level of RC structures. Expected damage due to corrosion has been generally defined based on the thresholds of corrosion rate and thus the loss in cross sectional area of reinforcement bars. By losing cross sectional area of reinforcement bars, the reinforcement bars might buckle before reaching their yield capacity. Moreover, the energy dissipation capacity reduces during an earthquake which also causes to have more brittle behaviour. However, a reduction in the performance level of RC structures does not only depend on losing cross sectional area of reinforcement bars. Expected damage according to corrosion rates based on previously defined thresholds [2-4] might be correct only if the loss of the cross sectional area of the reinforcement bars is considered while bond-slip relationships and reduced concrete compressive strength are neglected as a function of time. Corrosion can lead further structural distress due to loss of bond strength between concrete and reinforcement bars. The degradation of the bond strength causes an increase in the global drift ratio of RC structures which needs to be considered in non-linear seismic performance analyses. The bond-slip model developed by Alsiwat and Saatcioglu [5] indicates that results of member end rotations due to

\footnotetext{
*Corresponding author: Hakan Yalciner, Civil Engineering Department, Eastern Mediterranean University, Gazimagusa, Mersin 10, Turkey. E-mail: hakanyalciner@hotmail.com.
} 
slippage must be considered in inelastic analyses if reliable analytical predictions are sought. Another study done by Sezen and Moehle [6] to predict the anchorage slip of reinforcement bars indicated that slip deformations, even for non-corroded reinforcement bars, contribute $25 \%$ to $40 \%$ of the total lateral displacement. Moreover, when the cross sectional area of reinforcement decreases, the corrosion increases the corrosion product formation as a function of corrosion rate. The volume of corrosion rust is generally 2 to 4 times larger than the volume of the original reinforcement bars [7]. As a consequence of volumetric expansion, the concrete strength decreases as a function of crack width which also needs to be considered during assessment of corroded RC structures. For instance, an experimental study performed by Coronelli and Gambarova [8] investigated the ultimate bond strength and reduced concrete compressive strength of corroded reinforcement bars with different depths of corrosion attacks. Study performed by Coronelli and Gambarova [8] showed that the reduction in concrete compressive strength due to corrosion varied from $38 \%$ to $45 \%$. Although considerable research has been conducted on the effects of reinforcement corrosion, to the knowledge of the authors, incremental dynamic analysis (IDA) by considering the time-dependent seismic performance levels of corroded RC buildings has not been performed up to date. A partially similar study was conducted by Berto et al. [9]. In that study, push-over analyses were performed to predict the capacity curve of the corroded structure by considering only reduction in cross sectional area of reinforcement bars and assumed three different water-cement ratios of concrete. Only reduction in cross sectional area of reinforcement bars was considered as time-dependent in the study of Berto et al. [9] where bond-slip relationship was not taking into account. Moreover, the interest of previous studies was not to predict the seismic performance levels of corroded RC structures as a function of corrosion rate. Therefore, in this study, in contrast to previous corrosion models $[9,10]$ and assessment methods, three combined effects of corrosion (the loss of the cross sectional area of the reinforcement bars, the reduction of the concrete compressive strength and the bond-slip relationship) were used in nonlinear analyses to predict the time-dependent seismic performance levels of assessed RC building. Experimentally obtained corrosion rate and concrete compressive strength 25 years after construction were used to predict the loss in cross sectional area of reinforcement bars, reduction in concrete compressive strength and additional displacement due to slippage $\left(\Delta_{\mathrm{s}}\right)$ in reinforcement bars as a function of time.

It is important to consider carefully these three effects of corrosion on the seismic performance level as a function of time. Therefore, the modelling of plastic hinge properties plays an important role to combine these three effects. Thus, in this study, to ensure these three effects of corrosion on the seismic performance level, user-defined plastic hinge properties were modelled for each corresponding time period from the predicted time-dependent moment-curvature relationships. It should be noted all of the columns of the building in this study were exterior column and subject to aggressive weather condition and corroded. Thus, results presented in this study may be valid for such type of building with exterior columns.

\section{Description of the analyzed building}

In this study, a corroded, 25-year-old high school building which has been demolished at an earlier time was analyzed as a function of corrosion rate. Figures 1 and 2 show the general view and plan of analyzed high school building with dimensions of beams (dimensions in $\mathrm{cm}$ ), respectively. In Fig. 2, all columns have $30 \times 45 \mathrm{~cm}$ cross section. The plan of the building is symmetrical about in $\mathrm{X}$ direction having a total length and width of $37.37 \mathrm{~m}$ and $8.87 \mathrm{~m}$, respectively. The building has one story, with a total height of $4.10 \mathrm{~m}$. The distance from the building to the sea is $2380 \mathrm{~m}$, which gives an $85 \%$ probability of corrosion potential based on half-cell tests. The slab thickness of the building was $15 \mathrm{~cm}$, and the calculated additional dead and live loads of the slab were $1.5 \mathrm{kN} / \mathrm{m}^{2}$. The calculated total weight of the structure was $400 \mathrm{kN}$. The soil class was classified as soft clay (group D), the building importance factor was taken as 1.4, and the effective ground acceleration coefficient $\left(\mathrm{A}_{0}\right)$ was taken as $0.3 \mathrm{~g}$ (seismic zone 2) according to Turkish earthquake code 2007 [11]. The field evaluations were done in order to model and assess the $\mathrm{RC}$ structure by series of destructive and non-destructive tests. Because of safety issues where spalling of concrete was exited due to corrosion, the building was rounded by barrier tape for safety consideration after the primarily structural condition survey of the building. In order to identify the amount and dimensional properties of the reinforcement bars, selected columns faces were opened from the different point of the building. For the beams and the remaining columns, non-destructive (ferro scanning) method was used to define the amount of reinforcement bars. Figure 3 shows an opened outer column from the building. Most of the reinforcement details of beams were visible 
due to the volume expansion of the corrosion rust which caused spalling of concrete cover as shown in Fig. 4. Based on the experimental study, the measured concrete covers for the columns and beams were $3.5 \mathrm{~cm}$ where the details of the reinforcement bars are also shown in Figs 3 and 4, respectively.

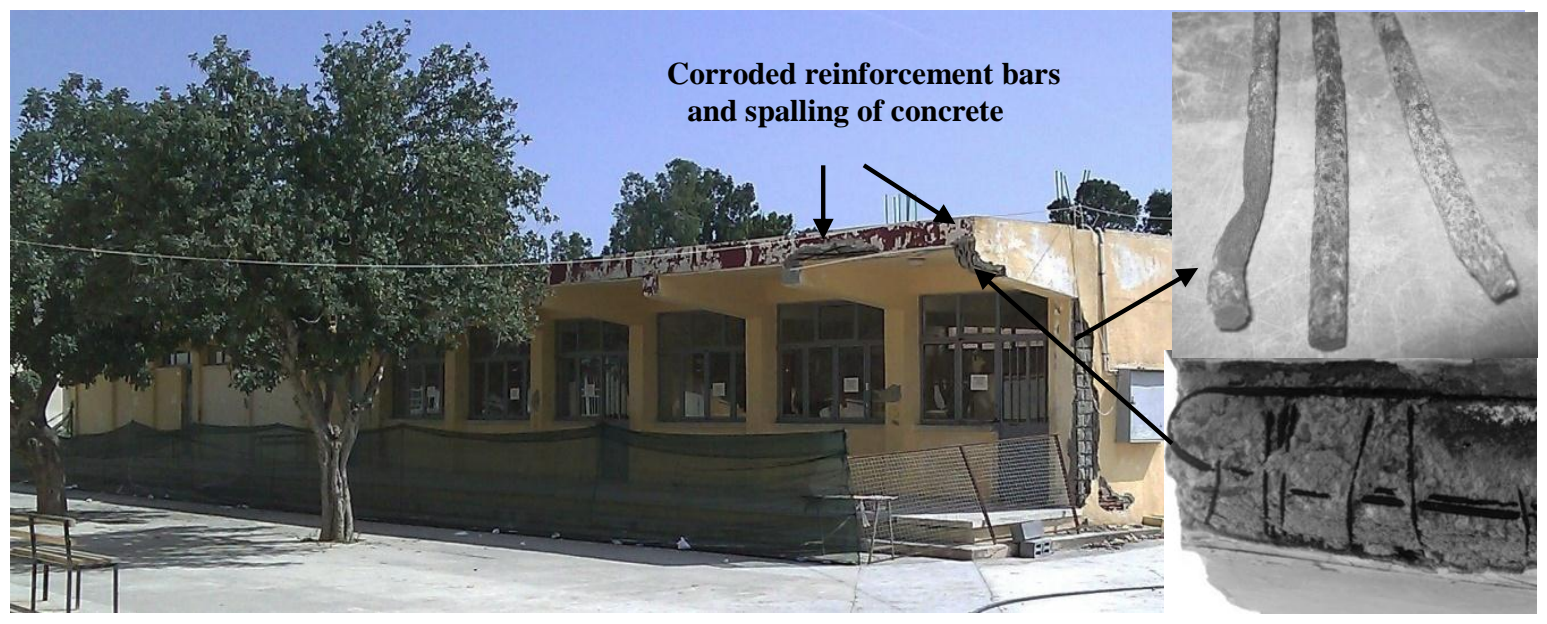

Fig. 1. Analyzed high school building.

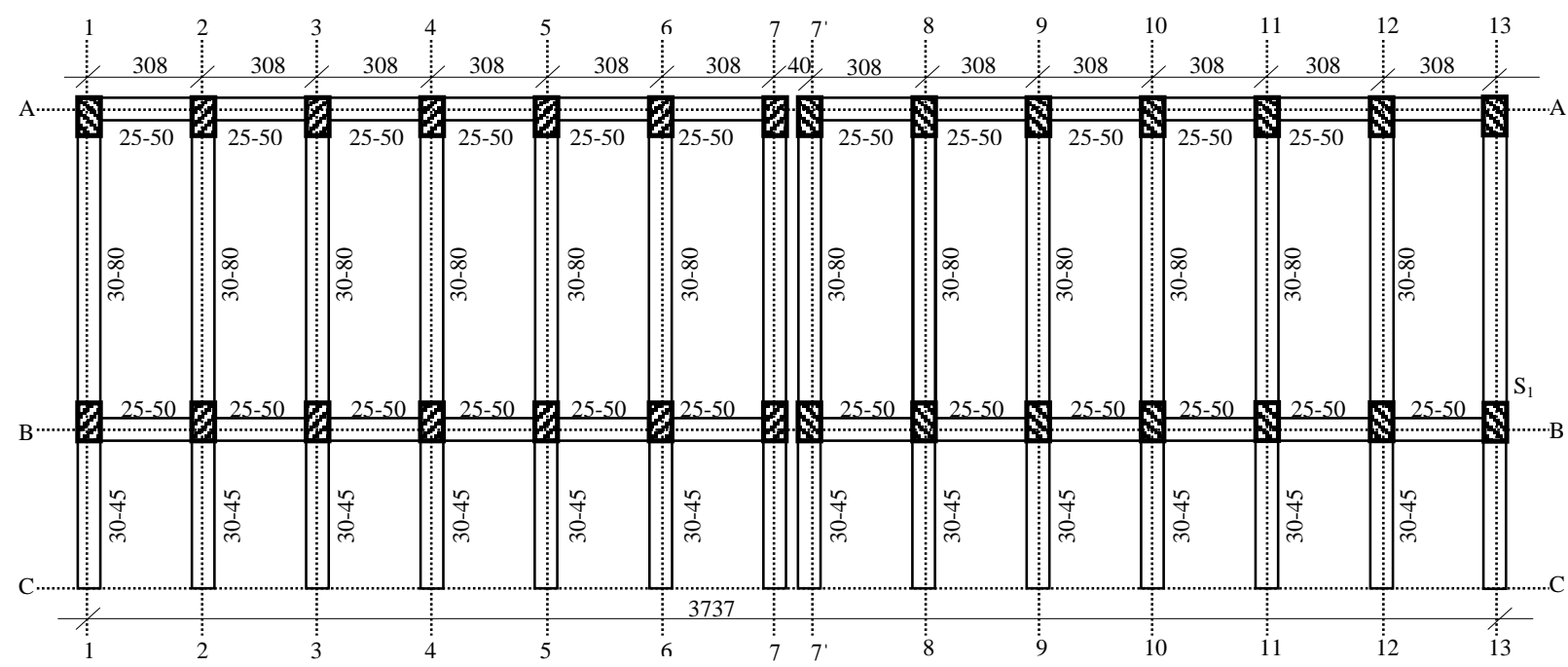

Fig. 2. Plan of building.

\section{Corrosion rate and non-linear material modelling}

A number of corroded and non-corroded reinforcement bars were taken from the building to investigate the mechanical properties and the corrosion rate of reinforcement bars. The mechanical properties of the non-corroded reinforcement bars where the yield strength $\left(f_{s y}\right)$ was $303 \mathrm{MPa}$, the rupture strength $\left(f_{s u}\right)$ was equal to $433 \mathrm{MPa}$, the yield strain $\left(\varepsilon_{s y}\right)$ was equal to 0.0015 , the strain hardening $\left(\varepsilon_{s h}\right)$ was equal to 0.011 , the rupture extension $\left(\varepsilon_{s u}\right)$ was equal to $16 \%$, and the elastic modulus of strain hardening region $\left(E_{s h}\right)$ was equal to $1745 \mathrm{MPa}$. The elastic modulus of concrete $\left(E_{c}=3250 \sqrt{f_{c}^{\prime}}+14000 \mathrm{MPa}\right.$ ) was calculated according to Turkish standard 500 [12]. In order to 


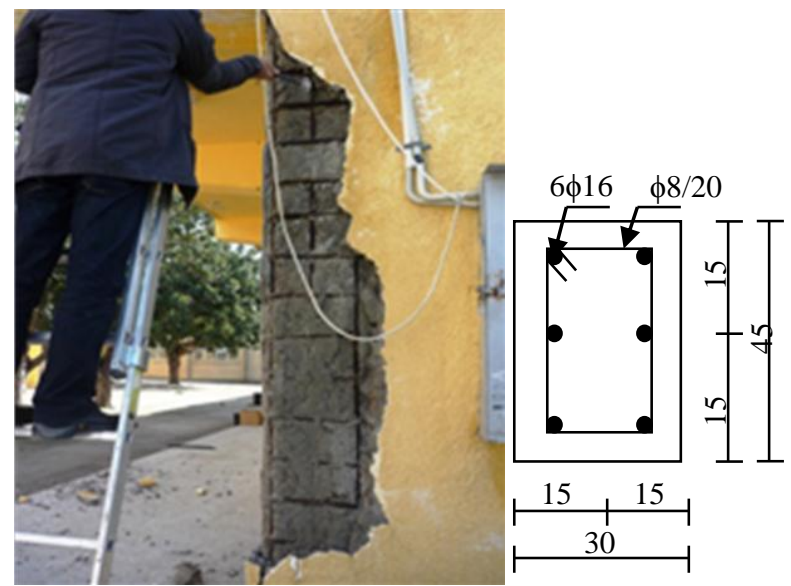

Fig. 3. Outface of $S_{1}$ column.

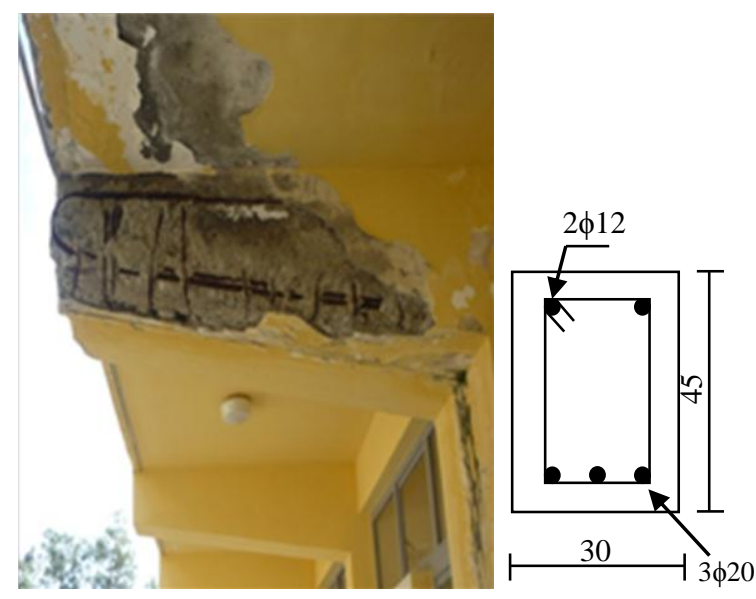

Fig. 4. Volume expansion of corrosion rust.

calculate the corrosion rate of reinforcement bars of columns and beams, chemical cleaning was done by using hydrochloric acid (12\% by weight of water) to remove the corrosion product from the surface of reinforcement bars according to the described standard ASTM G1-03 [13]. Calculated corrosion rate 25 years after construction was $2.43 \mu \mathrm{A} / \mathrm{cm}^{2}$ (conversion factor: $1 \mu \mathrm{A} / \mathrm{cm}^{2}$ is equal to $0.0116 \mathrm{~mm} /$ year). Thus, the calculated mass losses $\left(\Delta_{\mathrm{w}}\right)$ of longitudinal reinforcement bars of columns were $16.84 \%$ and $33.7 \%$ after 25 and 50 years, respectively $\left(\Delta_{\mathrm{w} 25}\right.$ : $\left.16.84 \%, \Delta_{\mathrm{w} 50}: 33.71 \%\right)$. Because of corrosion, the mechanical properties of a reinforcement bar change as a function of mass loss. Therefore, a well known empirical model developed by Lee and Cho [14] was used to predict the mechanical properties of corroded reinforcement bars. The model developed by Lee and Cho [14] calculates the yield point, the minimum rupture strength and the elastic modulus of corroded reinforcement bars by using Eqs (1) to (4).

$$
\begin{aligned}
& f_{c y}=\left(1-1.24\left(\Delta_{w} / 100\right)\right) f_{s y} \\
& f_{c s u}=\left(1-1.07\left(\Delta_{w} / 100\right)\right) f_{s u} \\
& E_{c s}=\left(1-0.75\left(\Delta_{w} / 100\right)\right) E_{s} \\
& \varepsilon_{c s u}=\left(1-1.95\left(\Delta_{w} / 100\right)\right) \varepsilon_{s u}
\end{aligned}
$$

where $f_{\text {cy }}$ is the yield strength, $E_{c s}$ is the elastic modulus, $f_{c s u}$ is the the rupture strength, and $\varepsilon_{c s u}$ is the rupture extension of corroded reinforcement bars. It might be useful to indicate that, there was a reasonable good agreement between obtained mechanical properties of corroded reinforcement bars in 25 years and developed empirical model by Lee and Cho [14]. In order to model the stress-strain relationships of confined columns, three models developed by Kent and Park [15], Saatcioglu and Razvi [16] and Mander et al. [17] were used. For each case (non-corroded (t: 0), 25 (existing), and 50 years), the models that gave higher demands (lower elastic and inelastic stiffness and lower yield strength) were selected to be used in nonlinear analyses. In order to model the stress-strain relationship of steel, the developed model by Mander [18] was used.

\section{Time-dependent behaviour of $\mathrm{RC}$ sections}

Experimentally obtained corrosion rate was used to predict the loss in cross sectional area of reinforcement bars, and the reduction in concrete strength as a function of time. Based on the experimental works and obtained corrosion rate, the loss in cross sectional area of reinforcement bars of columns after 25 and 50 years were $8.81 \%$ and $17.62 \%$, respectively. Once the corrosion rate is known as a function of time, the reduced concrete strength can be predicted 
as a function of time. In this study, a model developed by Vecchio and Collins [19] was used to predict the reduced concrete strength as a function of corrosion rate. The model developed by Vecchio and Collins [19] calculates the reduced concrete strength based on the total crack width $\left(w_{\mathrm{cr}}\right)$. However, the developed model by Vecchio and Collins [19] was not time-dependent to predict the reduced concrete strength as a function of given corrosion rate. A study by Coronelli and Gambarova [8] suggested adopting the crack width model of Molina et al. [20] into the model developed by Vecchio and Collins [19] to calculate the reduced concrete strength. Molina et al. [20] assumed that the volumetric expansion of the oxides with respect to the virgin material was equal to 2 , and thus the diameter of each bar was assumed to increase by two times the depth of the corrosion attack. Therefore, $w_{c r}$ was expressed by Eq. (5):

$$
w_{c r}=\sum u_{i c o r r}=2 \pi\left(v_{r s}-1\right) X
$$

where $v_{r s}$ is the ratio of the volumetric expansion of the oxides with respect to the virgin material, $X$ is the depth of the corrosion attack, and $u_{i \text { corr }}$ is the opening of each single corrosion crack. In this study, in order to predict the time-dependent crack width as a function of corrosion rate, the attack penetration was predicted according to the well know Faraday's law [21] and adopted into the model developed by Molina et al. [20]. The attack penetration by Faraday's law [21] is given in Eq. (6).

$$
X=0.0116 . I_{\text {corr }} t
$$

where $I_{\text {corr }}$ is the corrosion intensity $\left(\mu \mathrm{A} / \mathrm{cm}^{2}\right), t$ is the time in years, and 0.0116 is a conversion factor of $\mu \mathrm{A} / \mathrm{cm}^{2}$ into $\mathrm{mm} /$ year for steel. As shown in Eq. (6), the attack penetration is a function of corrosion rate. Thus, predicted time-dependent attack penetration gives the time-dependent crack width as a function of corrosion rate (see Eq. (5)). The calculation of the time-dependent crack width provides a time-dependent reduced concrete strength by using the model developed by Vecchio and Collins [19]. The ratio of the volumetric expansion of the oxides with respect to the virgin material was assumed to be same for all reinforcement bars and taken as 2 according to experimental works. As a consequence of increases in tensile strain in concrete due to corrosion, the calculated reduced concrete strength after 25 and 50 years was $20.25 \mathrm{MPa}$ and $17 \mathrm{MPa}$, respectively. The predicted loss of cross sectional area in the reinforcement bars and the reduced concrete compressive strength were used to predict the time-dependent moment-curvature relationships. For each column and beam of three different time periods (t: $0, \mathrm{t}: 25$ and $\mathrm{t}: 50$ years), a total of 63 time-dependent moment-curvature relationships were predicted as a function of corrosion rate for three different models, one developed by Kent and Park [15] and the others by Saatcioglu and Razvi [16] and Mander et al. [17]. The predicted time-dependent moment-curvature relationships of $S_{1}$ column is shown in Fig. 5.

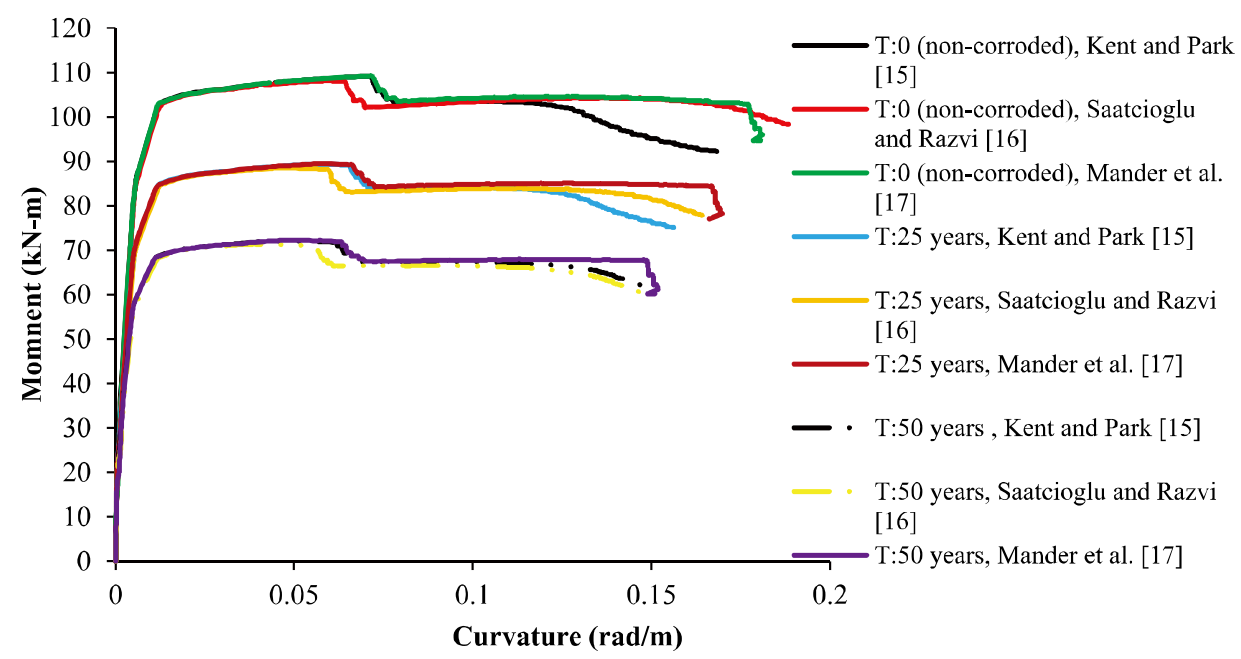

Fig. 5. Time-dependent moment-curvature relationships of $S_{1}$ column. 


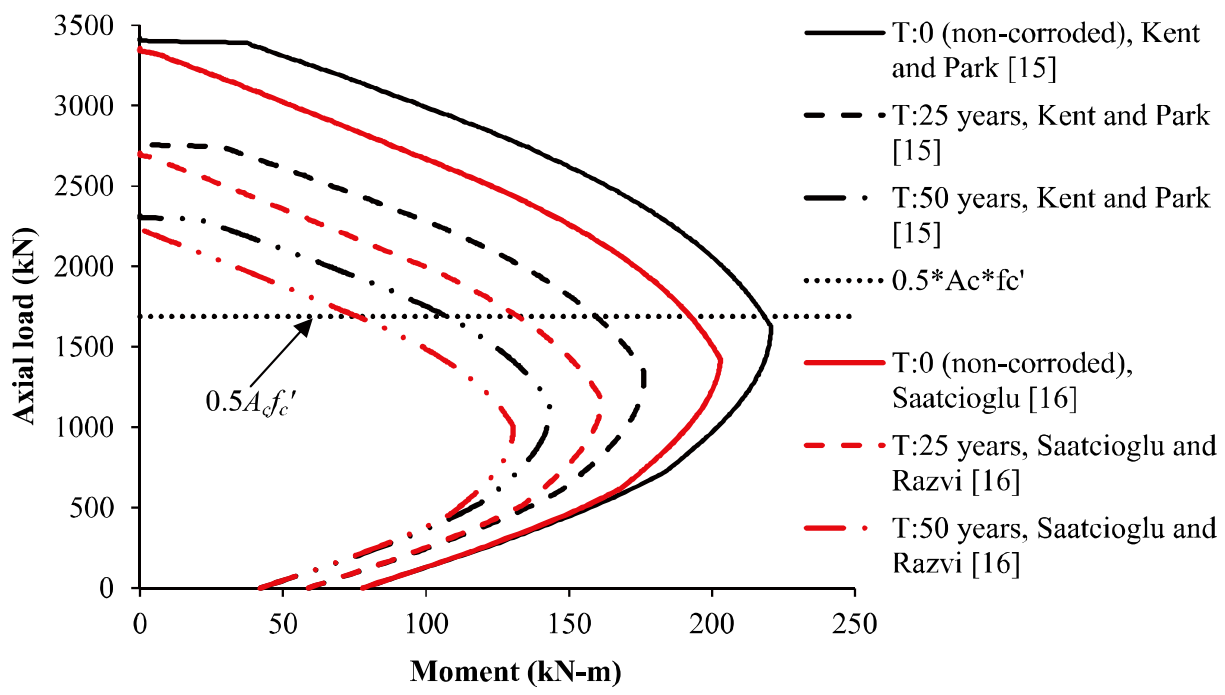

Fig. 6. Time-dependent M-N diagrams.

In Fig. 5, the predicted moment-curvature relationships show the behaviour of a RC column under the impact of the corrosion. In Fig. 5, the area under the curvature represents the stored or dissipated energy by RC columns. Due to time-dependent corrosion effects, dissipated energy by a RC column decreases as a function of time while the rotation increases for lower moment values, which increases the lateral displacement. The reduction in load carrying capacity of a RC column subjected to axial loading can be evaluated from a moment-load (M-N) interaction diagram. The results of the time-dependent M-N interaction diagrams of the $S_{1}$ column is plotted in Fig. 6 as a function of corrosion rate by considering two different models developed by Kent and Park [15] and Saatcioglu and Razvi [16]. The results of the model developed by Mander et al. [17] was very close to the developed model by Kent and Park [15]. In Fig. 6, the line of $0.5 A_{c} f_{c}{ }^{\prime}$ represents the maximum allowable load that can be carried by a section according to TEC 2007 [11], where $A_{c}$ is the gross sectional area of a section. On this line, the moment capacity of a corroded RC section decreases as a function of time due to corrosion. For instance, when time is equal to zero (non-corroded), the moment capacity of the $S_{1}$ column based on the Kent and Park model [15] is $219 \mathrm{kN}-\mathrm{m}$ on this line, but this capacity decreases to $167 \mathrm{kN}-\mathrm{m}$, and $118 \mathrm{kN}-\mathrm{m}$ after 25 (existing structure), and 50 years, respectively. Based on results of the time-dependent moment-curvature relationships, there is not much difference between the models developed by Kent and Park [15], Saatcioglu and Razvi [16] and Mander et al. [17]. Therefore, the authors of this article used the results of the model developed by Kent and Park [15] for time-dependent moment-curvature relationships.

\section{Capacity curve of the building as a function of corrosion rate}

Non-linear static push-over analyses were performed for each time period (t: $0, \mathrm{t}: 25$ and $\mathrm{t}: 50$ years) as a consequence of two corrosion effects (the loss in cross sectional area of reinforcement bars and the reduction in concrete strength). The SAP 2000 [22] program was used to analyze the structure. The vertical distributed and earthquake loads that were used in the analyses are depicted in Fig. 7. Additional eccentricity effects $\pm 5 \% \mathrm{E}_{\mathrm{x}}$ and $\mathrm{E}_{\mathrm{y}}$ were also considered in the analyses. In order to ensure the effects of corrosion on the structural behaviour during push-over analyses, for each time period of structural members, user-defined plastic hinge properties were calculated from the predicted time-dependent moment-curvature relationships (see Fig. 5). The length of the plastic hinges was taken into account by using moment-rotation relationships instead of moment-curvature relationships. Therefore, predicted time-dependent moment-curvature relationships were used to calculate time-dependent moment-rotation relationships where the rotation of the plastic hinges is the interaction between the length of the plastic hinges and curvature at a point. For each time period, the calculated plastic hinge properties were assigned to each both ends of the beams and the columns of the assessed building according to the corresponding time periods. Thus, the assessed 
building was analyzed according to its own deformation capacity under the time-dependent effects of corrosion. The locations of the plastic hinges of the structural members were located according to the study done by Inel and Ozmen [23].

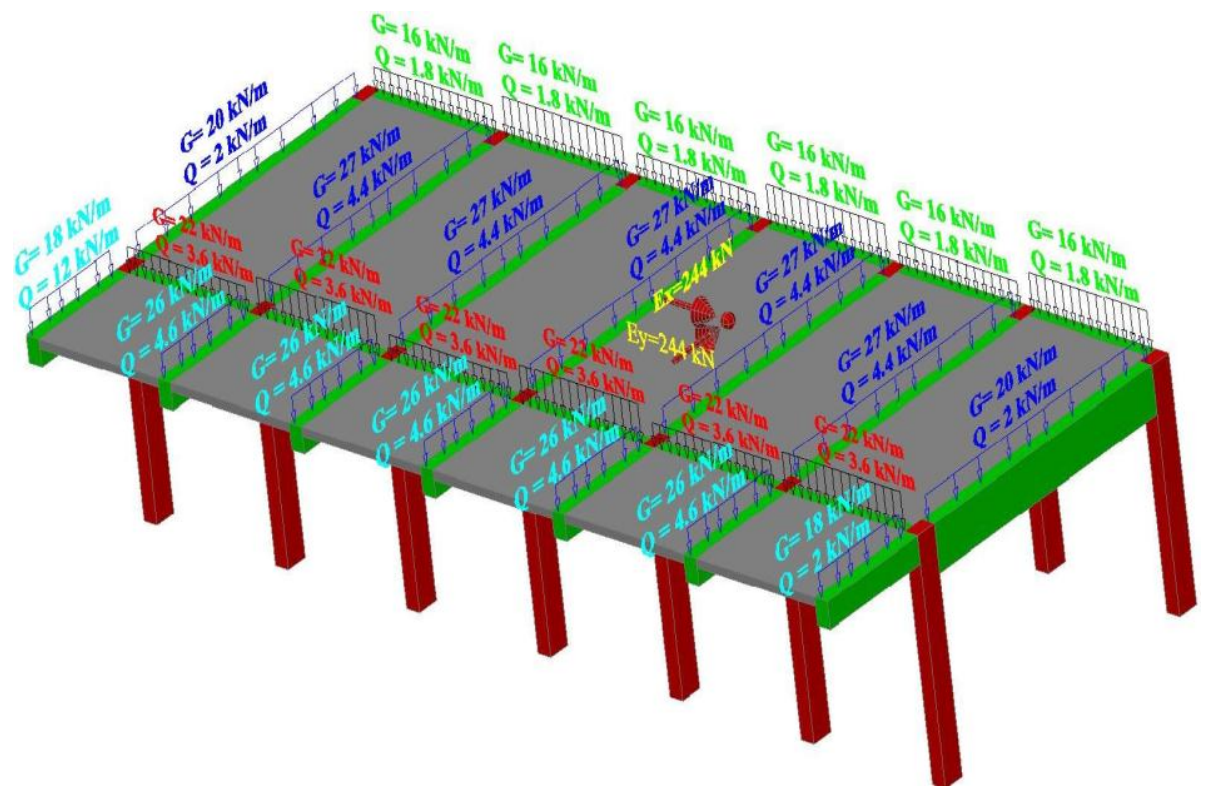

Fig. 7. Used vertical and earthquake loads in the analyses.

Figure 8 shows the comparison between the capacity curves plotting the base shear force against the control displacement for the structure in non-corroded and for other two different time periods as a function of corrosion rate.

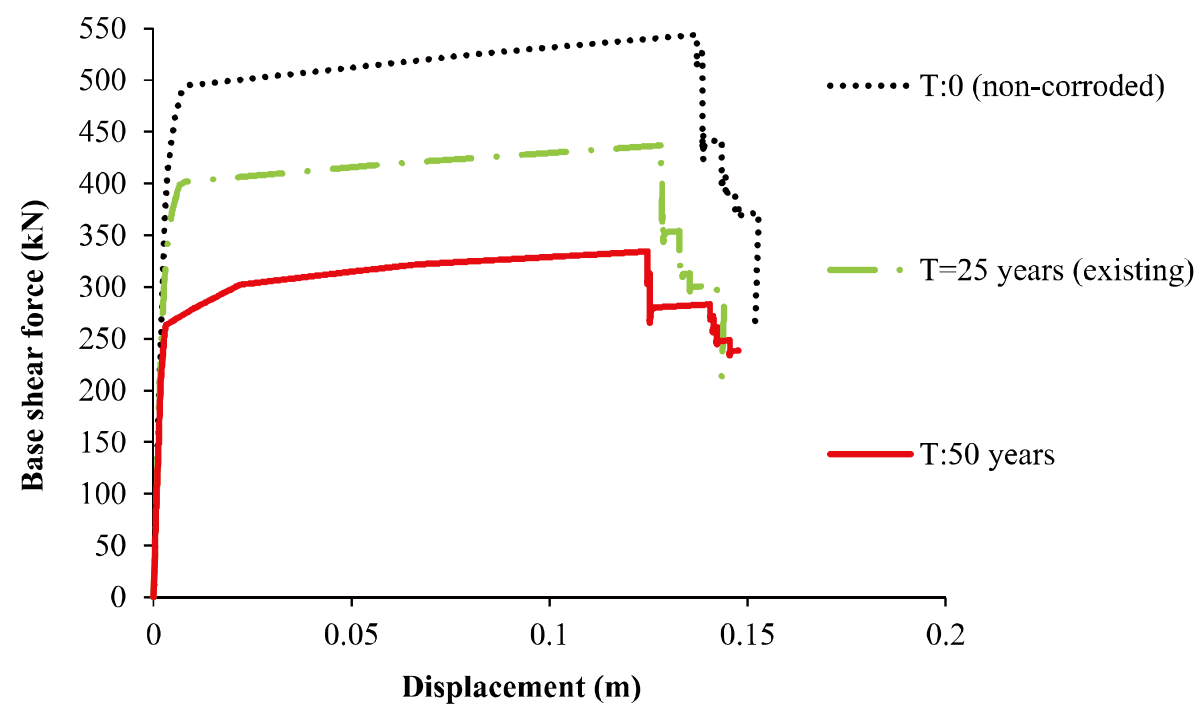

Figure 8 . Time-dependent capacity curves for non-corroded and corroded building.

As shown in Fig. 8, there is a serious reduction of the load bearing capacity for the corroded structure with respect to non-corroded structure. The results significantly indicate that for the same amount of base shear force dis- 
placement increases as a function of time due to corrosion. Moreover, it can be observed that the mechanism of plastic hinges was affected by corrosion. For instance, the collapse mechanism of non-corroded structure which starts at a top displacement of $0.137 \mathrm{~m}$ when the base shear force is $544 \mathrm{kN}$. However, for the time periods of 25 (existing) and 50 years, collapse mechanism starts at a top displacement of $0.128 \mathrm{~m}$ and $0.124 \mathrm{~m}$ when the base shear force is $437 \mathrm{kN}$ and $334 \mathrm{kN}$, respectively.

\subsection{Capacity curve of the building by modified plastic hinge properties due to slippage}

Because of corrosion, the bond strength in $\mathrm{RC}$ members decreases which cause to increase the displacement of the global structure by slippage of reinforcement bars. Previously predicted base shear force against the control displacement (see Fig. 8) was performed without considering the bond-slip relationships. Proposed model by Sezen and Setzler [24] was used to calculate slip rotation $\left(\theta_{\mathrm{s}}\right)$ by using Eqs (7) and (8).

$$
\begin{aligned}
& \theta_{s}=\frac{\varepsilon_{s} f_{s} d_{b}}{8 u_{b}(d-c)} \text { for } \varepsilon_{s} \leqslant \varepsilon_{y} \\
& \theta_{s}=\frac{d_{b}}{8 u_{b}(d-c)}\left(\varepsilon_{y} f_{y}+2\left(\varepsilon_{s}+\varepsilon_{y}\right)\left(f_{s}-f_{y}\right)\right) \text { for } \varepsilon_{s}>\varepsilon_{y}
\end{aligned}
$$

where $d_{b}$ is the diameter of the reinforcement bars, $d$ is the section depth, and $c$ is the neutral axis depth. The developed model by Sezen and Setzler [24] was performed for non-corroded reinforcement bars, thus uniform bond stress $\left(u_{b}\right)$ was assumed. In this study, in order to predict the slip rotation as a function of mass loss due to corrosion, the bond stress was adopted from the study done by Lee et al. [25] instead of the uniform bond stress assumed by Sezen and Setzler [24]. The model developed by Lee et al. [25] to predict the ultimate bond stress as as function of mass loss is given by Eq. (9).

$$
u_{b}=5.21 e^{-0.0561 \Delta_{w}}
$$

As shown in Eqs (7) and (8), slip rotation is dependent on the strain and stress in reinforcement bars. Since, mechanical properties of reinforcement bars change as a function of mass loss, slip rotation can be calculated as a function of time. The results of force and corresponding maximum moment from the predicted first pushover analyses (see Fig. 8) were used to predict the time-dependent slip rotation by using Eqs (7) and (8). In order to obtain time-dependent slip rotation due to corrosion, time-dependent moment-curvature relationships were used to calculate the strain and stress in the reinforcing bar as a consequence of corrosion effects. The time-dependent relationships between calculated maximum moments and corresponding slip rotations and displacements of the reinforcement bars embedded in $S_{1}$ column are shown in Figs 9 and 10, respectively.

In order to ensure the effect of time-dependent bond-slip relationships due to corrosion on the structural behaviour, the previously defined plastic hinge properties need to be modified. Therefore, predicted time-dependent slip rotations (see Fig. 9) were used to modify the time-dependent moment-curvature relationships (see Fig. 5). For each time period of structural member, plastic hinge properties were redefined by taking into account the effect of bond-slip relationships. Second push-over analyses by considering the effect of bond-slip relationship were performed. The predicted time-dependent capacity curve due to slippage of reinforcement bars and general deformation due to slip are shown in Fig. 11.

\section{Seismic performance analyses}

Incremental dynamic analyses (IDA) were performed to predict the performance level of the assessed building as a function of corrosion rate. For IDA, the 5\% damped first-mode spectral acceleration $\left(S_{a}\left(T_{1}, 5 \%\right)\right)$ was selected. Twenty ground motion records were used to predict the performance levels of the building as a function of time, where the selected 12 motions records of pseudo velocity versus to period in seconds are shown in Fig. 12. 


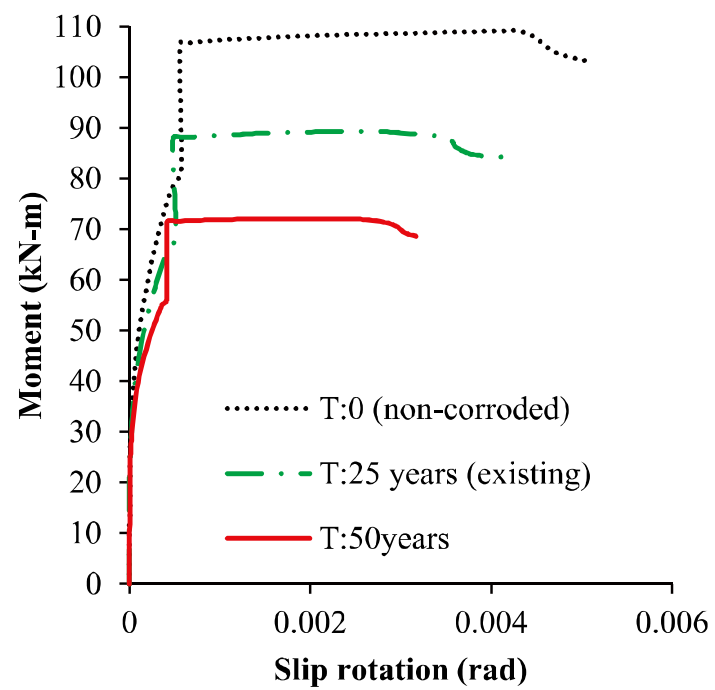

Fig. 9. Time-dependent slip rotation.

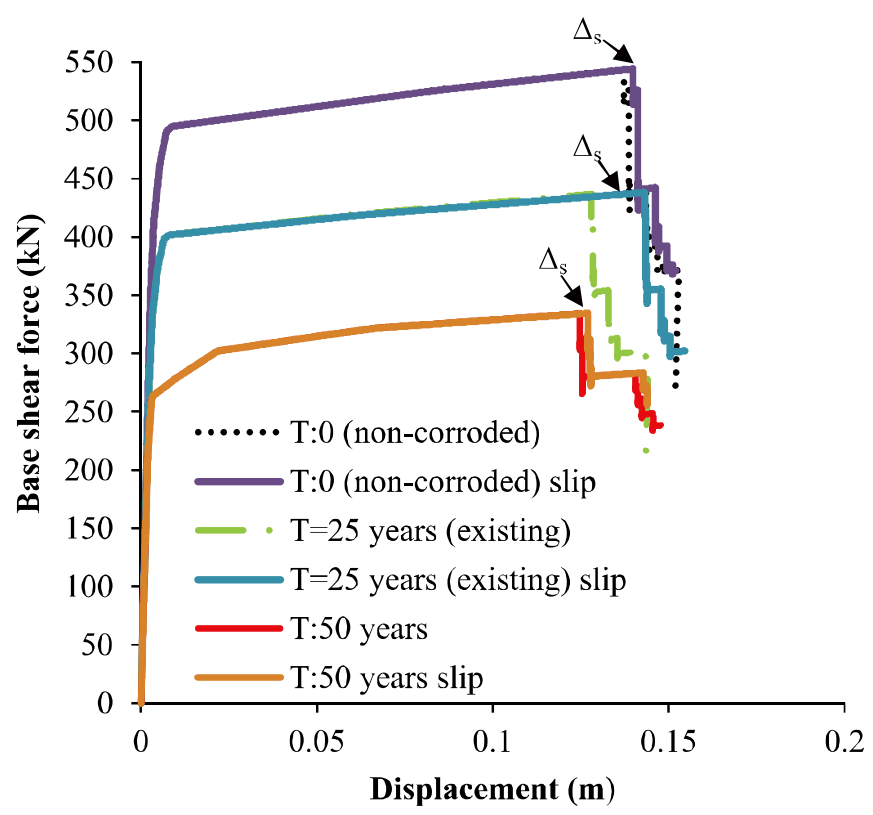

(a)

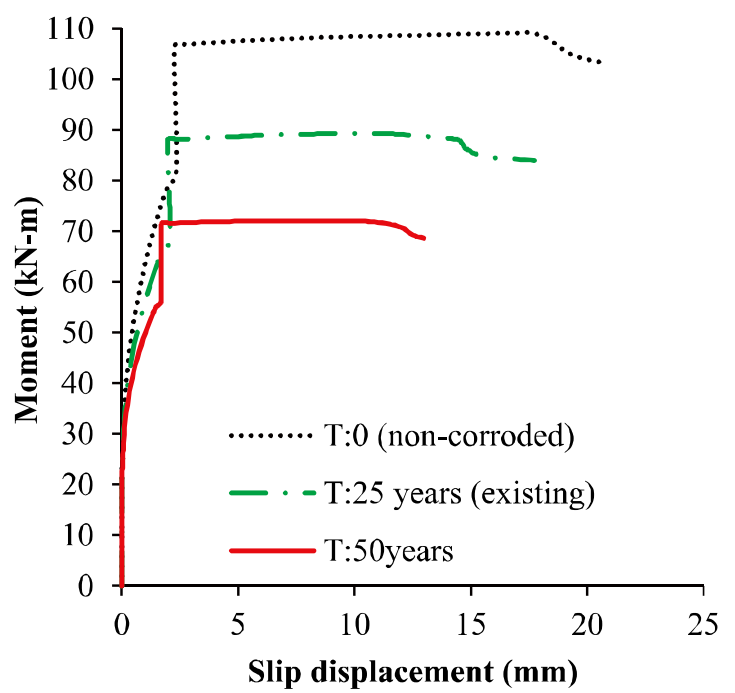

Fig. 10. Time-dependent slip displacement.

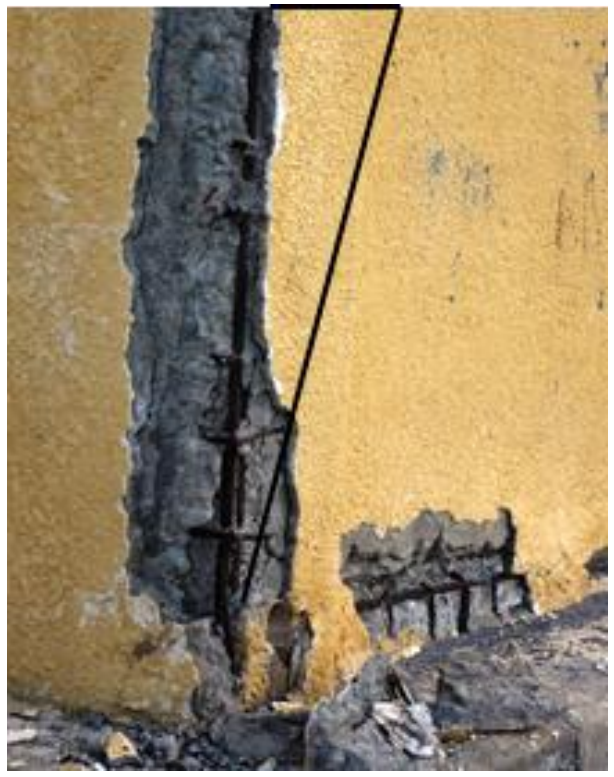

(b)

Fig. 11. (a): Time-dependent capacity curves by bond-slip relationships, (b): Slip deformation.

Figure 13 shows the IDA curves of non-corroded and existing ( $\mathrm{t}: 25$ years) building. As it is shown in Fig. 13, due to effects of corrosion premature dynamic instability occurs at the flat lines, where the roof drift ratio of corroded structure is greater than non-corroded structure. There are still contradictions existing in the available literature about defining the limit states of performance levels. Results of time-history analyses of non-corroded building showed that flat line at $S_{a}\left(T_{1}, 5 \%\right)$ occurred around $1.5 \%$ of roof drift ratio. Therefore, associated roof drift ratio corresponding to performance level of collapse prevention (CP) was selected as $1.5 \%$ while $0.5 \%$ and $1 \%$ were selected for immediate occupancy (IO) and life safety (LS), respectively. A probabilistic analysis is required to predict the performance level of the building as a function of time. The predicted lognormal fragility curves in terms 


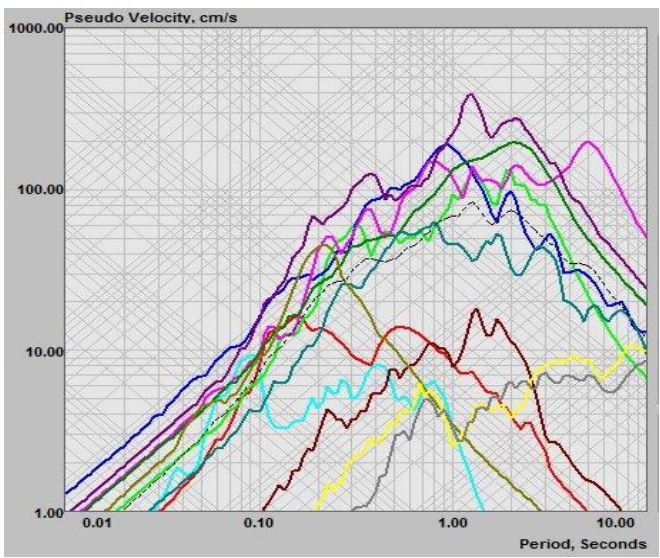

Fig. 12. Pseudo velocity spectrum for used ground motion records.

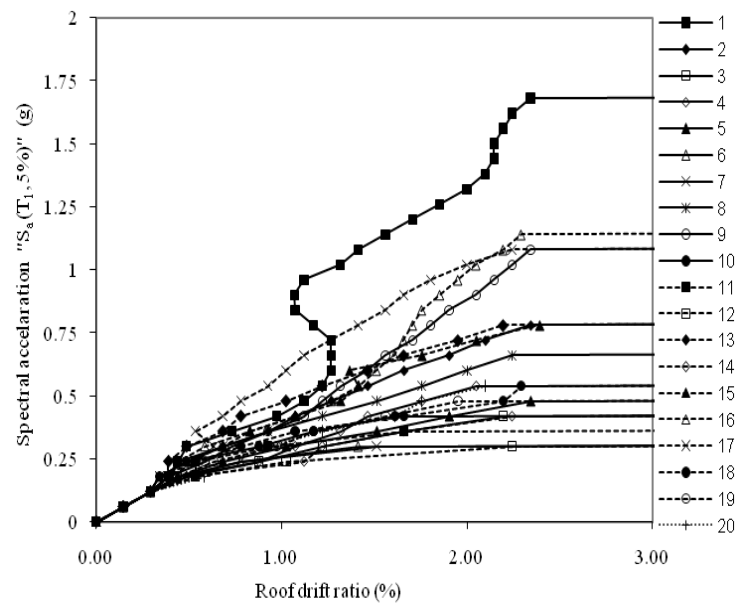

(a)

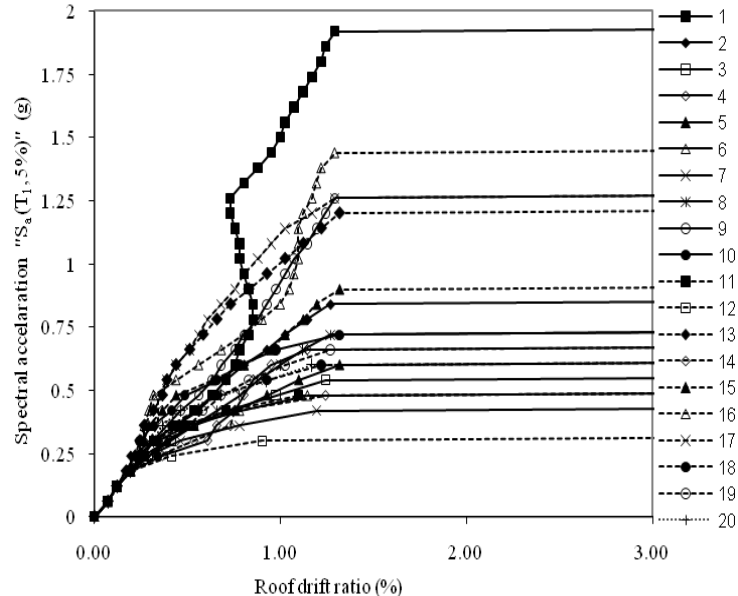

(b)

Fig. 13. IDA curves: (a) T: 0 (non-corroded), (b) T: 25 years (existing).

of peak ground acceleration (PGA) at the performance level of collapse prevention (CP) are shown in Fig. 14. In Fig. 14, for the non-corroded building, the probability of exceeding the limit state corresponding to CP is $46 \%$ when the PGA is equal to $0.75 \mathrm{~g}$. As shown in Fig. 14, this probability of exceeding increases as a function of time and shows different results according to the considered effects of corrosion. Therefore, the comparisons of the effects of corrosion by only loss of cross sectional area $\left(\mathrm{d}_{\mathrm{b}}\right)$ of reinforcement bar, and the combined three effects of corrosion due to bond-slip relationships and reduction in concrete strength are also shown in Fig. 14. As shown in Fig. 14, the reduction in the performance level of the building does not only depend on losing cross sectional area $\left(\mathrm{d}_{\mathrm{b}}\right)$ of reinforcement bars where the reduction in the bond strength and thus slippage of reinforcement bars due to corrosion needs to be considered for seismic analysis. For instance, in Fig. 14, 25 years after construction (T: 25 years, $\mathrm{d}_{\mathrm{b}}$ ), if only the loss of cross sectional area of reinforcement bars is considered; the probability of exceeding the limit state corresponding to $\mathrm{CP}$ is $55 \%$ when PGA is equal to $0.75 \mathrm{~g}$. However, this probability of exceeding increased to $77 \%$ for the same PGA when the three effects of corrosion were taken into account ( $\mathrm{T}: 25$ years, $\mathrm{d}_{\mathrm{b}}+$ bond-slip). For the same PGA of 50 years after construction ( $\mathrm{T}: 50$ years, $\mathrm{d}_{\mathrm{b}}+$ bond-slip); the probability of exceeding the limit state is $84 \%$ while this probability is $62 \%$ if only $\mathrm{d}_{\mathrm{b}}$ is considered. The time-dependent results clearly show that the probabilities of exceeding of limit state increase as a function of corrosion rate which causes to reduce the performance level of the structure. 


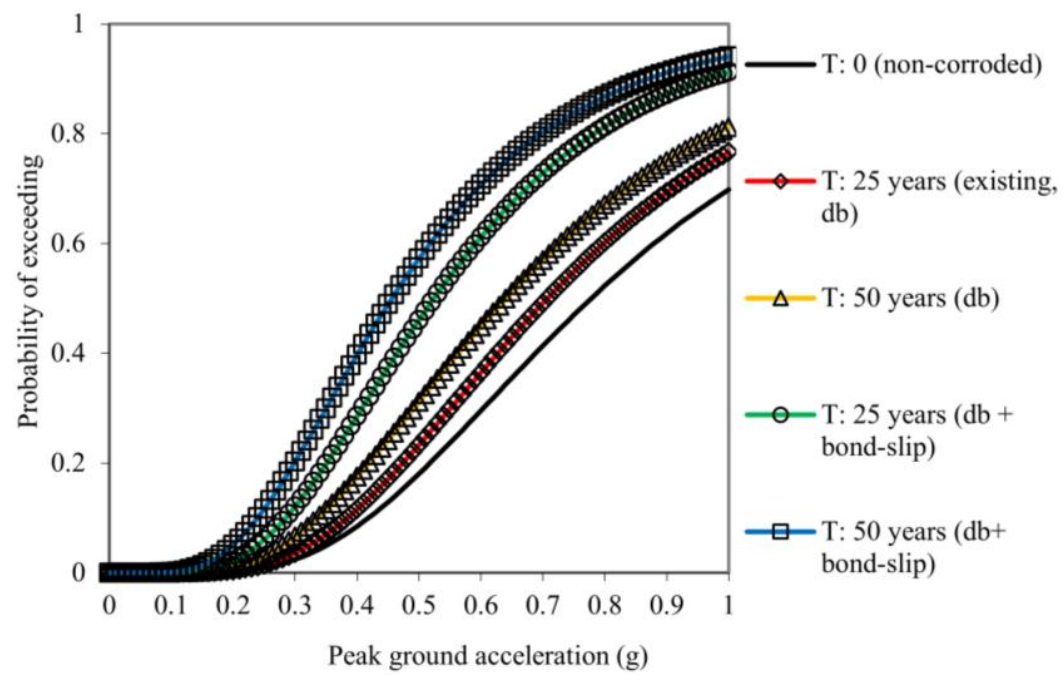

Fig. 14. Time-dependent fragility curves for the collapse prevention limit state.

\section{Conclusion}

A corroded, 25-year-old high school building was analyzed as a function of corrosion rate for different time periods. As a consequence of corrosion effects, plastic hinge properties were calculated as a function of corrosion rate. Additional displacement due to slippage of reinforcement bars by losing bond strength due to corrosion was considered to predict the time-dependent seismic performance levels of the RC building. The present study showed that service life of concrete structures is limited by corrosion of reinforcement where the quality of concrete, mainly the permeability, and the cover thickness and environmental factors affect the remaining service life of structures. Because of time-dependent effects of corrosion, not only safety issue, but also economical problem was occurred 25 years after construction of the building. Developed time-dependent fragility curves for the 25 years old RC building revealed that effect of bond strength on the seismic performance level is considerably high. It should be noted that for the peak ground acceleration equal to $0.4 \mathrm{~g}$, the probability of exceeding the collapse prevention limit state would be approximately 0.30 which is not acceptable for a school building. It can be concluded that, the safety and serviceability assessment of corroded RC structures need to be performed by the time-dependent variations.

\section{References}

[1] C.Q. Li, J.J. Zheng, R.E. Melchers and J.J. Zheng, Analytical model for corrosion-induced crack width in reinforced concrete structures, ACI Structural Journal 103(4) (2006), 479-487.

[2] W.J. McCarter and Ø. Vennesland, Sensor systems for use in reinforced concrete structures, Construction and Building Materials 18(6) (2004), 351-358.

[3] H.W. Song and V. Saraswathy, Corrosion monitoring of reinforced concrete structures-A Review, International Journal of Electrochemical Science 2 (2007), 1-28.

[4] R.K. Dhir, M.R. Jones and M.J. McCarthy, PFA concrete: Chloride-induced reinforcement corrosion, Magazine of Concrete Research 46(169) (1994), 269-77.

[5] J.M. Alsiwat and M. Saatcioglu, Reinforcement anchorage slip under monotonic loading, ASCE Journal of Structural Engineering 118(9) (1992), 2421-2438.

[6] H. Sezen and J.P. Moehle, Seismic test of concrete columns with light transverse reinforcement, ACI Structural Journal 103(6) (2006), 824-849.

[7] Z.P. Bažant, Physical model for steel corrosion in concrete sea structures-application, ASCE Journal of Structural Division 105(6) (1979), $1155-1166$.

[8] D. Coronelli and P. Gambarova, Structural assessment of corroded reinforced concrete beams: Modeling guidelines, ASCE Journal of Structural Engineering 130(8) (2004), 1214-1224. 
[9] L. Berto, R. Vitaliani, A. Saetta and P. Simioni, Seismic assessment of existing RC structures affected by degradation phenomena, Journal of Structural Safety 31(4) (2009), 284-297.

[10] D.E. Choea, P. Gardonia, D. Rosowskya and T. Haukaas, Seismic fragility estimates for reinforced concrete bridges subject to corrosion, Journal of Structural Safety 31(4) (2009), 275-283.

[11] Turkish Ministry of Public Works and Settlement, Specification for structures to be built in disaster areas, Ankara, Turkey, 2007.

[12] Turkish Standards Institute, TS500, Requirements for design and construction of reinforced concrete structures, Ankara, Turkey, 2000.

[13] ASTM G1-03, Standard Practice for Preparing, Cleaning, and Evaluating Corrosion Test Specimens, West Conshohocken, United States, 2003.

[14] H.S. Lee and Y.S. Cho, Evaluation of the mechanical properties of steel reinforcement embedded in concrete specimen as a function of the degree of reinforcement corrosion, International Journal of Fracture 157(1-2) (2009), 81-88.

[15] D.C. Kent and R. Park,Flexural members with confined concrete, ASCE Journal of the Structural Division 97(7) (1971), 1969-1990.

[16] M. Saatcioglu and S.R. Razvi, Strength and ductility of confined concrete, ASCE Journal of Structural Engineering 118(6) (1992), $1590-1607$.

[17] J.B. Mander, M.J.N. Priestley and R. Park, Observed Stress-Strain Behaviour of Confined Concrete, ASCE Journal of Structural Engineering 114(8) (1988), 1827-49.

[18] J.B. Mander, Seismic Design of Bridge Piers, Ph.D. thesis, University of Canterbury, New Zealand, 1984.

[19] F. Vecchio and M.P. Collins, The modified compression field theory for reinforced concrete elements subjected to shear, ACI Structural Journal 83(2) (1986), 219-231.

[20] F.J. Molina, C. Alonso and C. Andrade, Cover cracking as a function of rebar corrosion, part 2: Numerical model, Materials and Structures 26(9) (1993), 532-548.

[21] A. Bentur, S. Diamond and N.S. Berke, Steel corrosion in concrete: fundamentals and civil engineering practice, E\&FN Spon, London, UK, 1997.

[22] CSI, SAP2000 V-14., Integrated finite element analysis and design of structures basic analysis reference manual, Berkeley (CA, USA), Computers and Structures Inc., 2009.

[23] M. Inel and H.B. Ozmen, Effects of plastic hinge properties in nonlinear analysis of reinforced concrete buildings, Journal of Engineering Structures 28(11) (2006), 1494-1502.

[24] H. Sezen and E.J. Setzler, Reinforcement slip in reinforced concrete columns, ACI Structural Journal 105(3) (2008), $280-289$.

[25] H.S. Lee, T. Noguchi and F. Tomosawa, Evaluation of the bond properties between concrete and reinforcement as a function of the degree of reinforcement corrosion, Cement and Concrete Research 32(8) (2002), 1313-1318. 

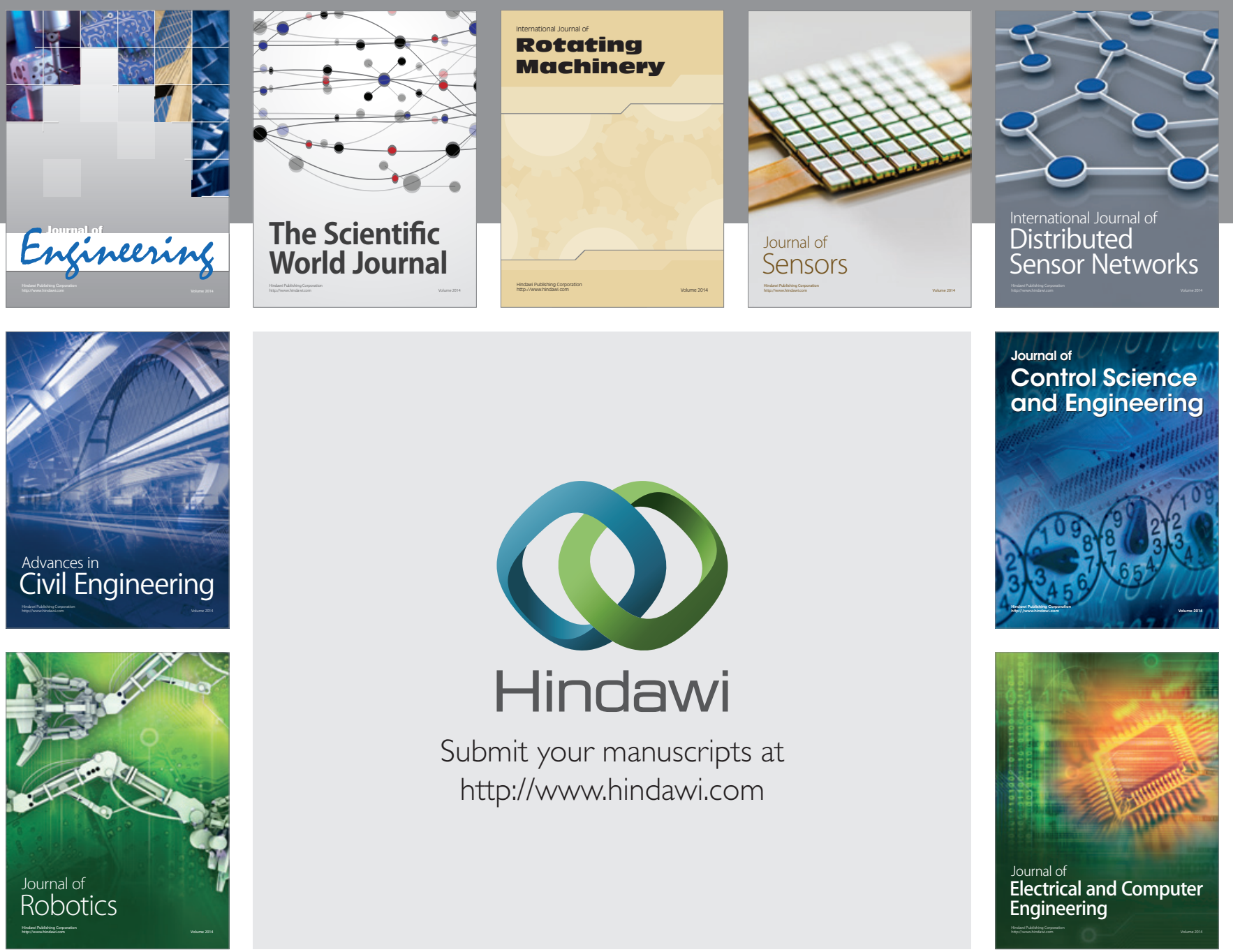

Submit your manuscripts at

http://www.hindawi.com
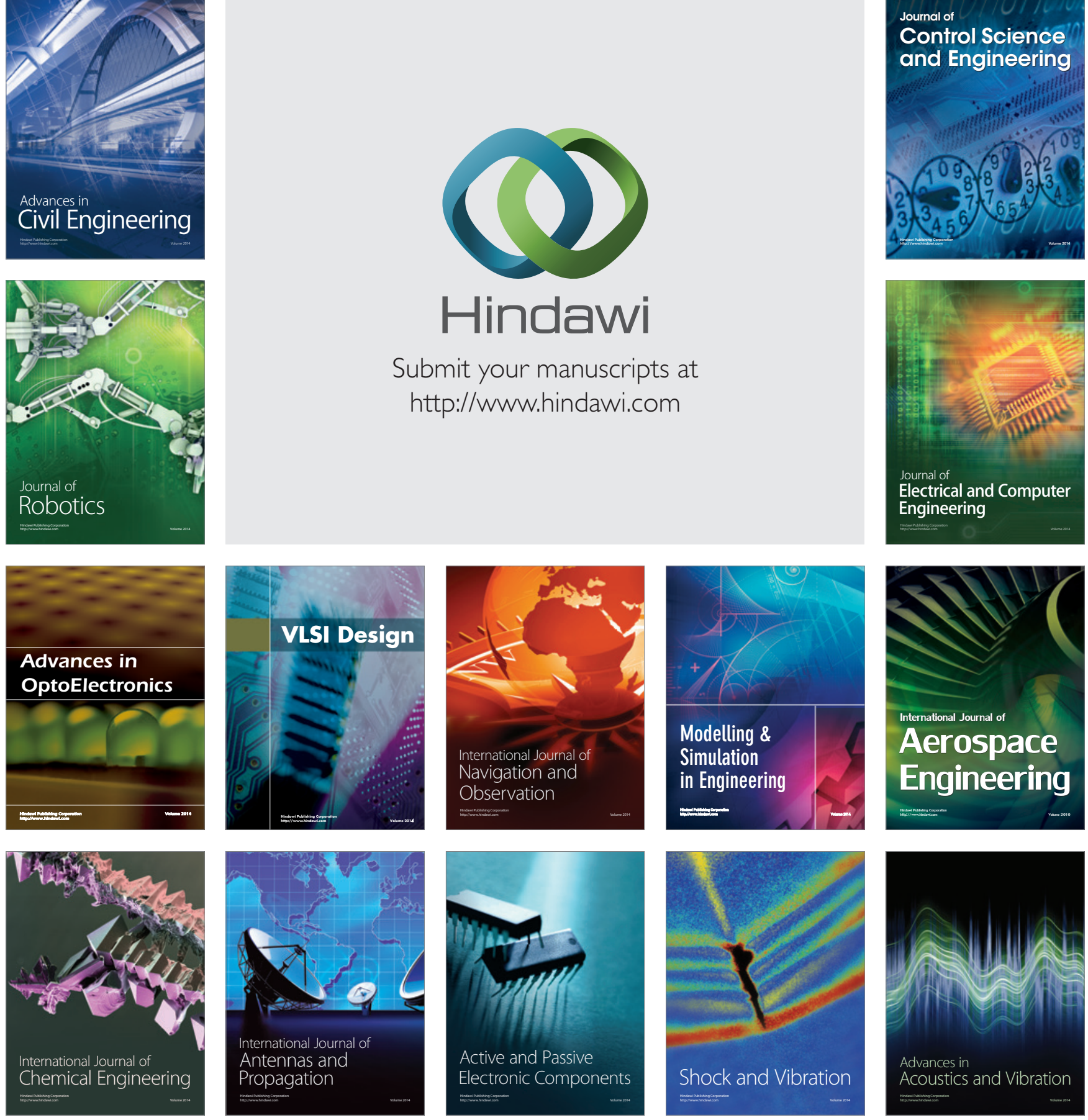